\title{
CALCULATIONS OF BURNUP \\ AND DAMAGE \\ FOR FAST REACTOR FUELS
}

APRIL 1970

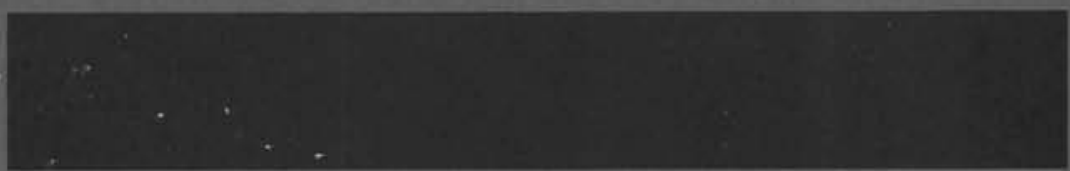

AEC RESEARCH \& DEVELOPMENT REPORT

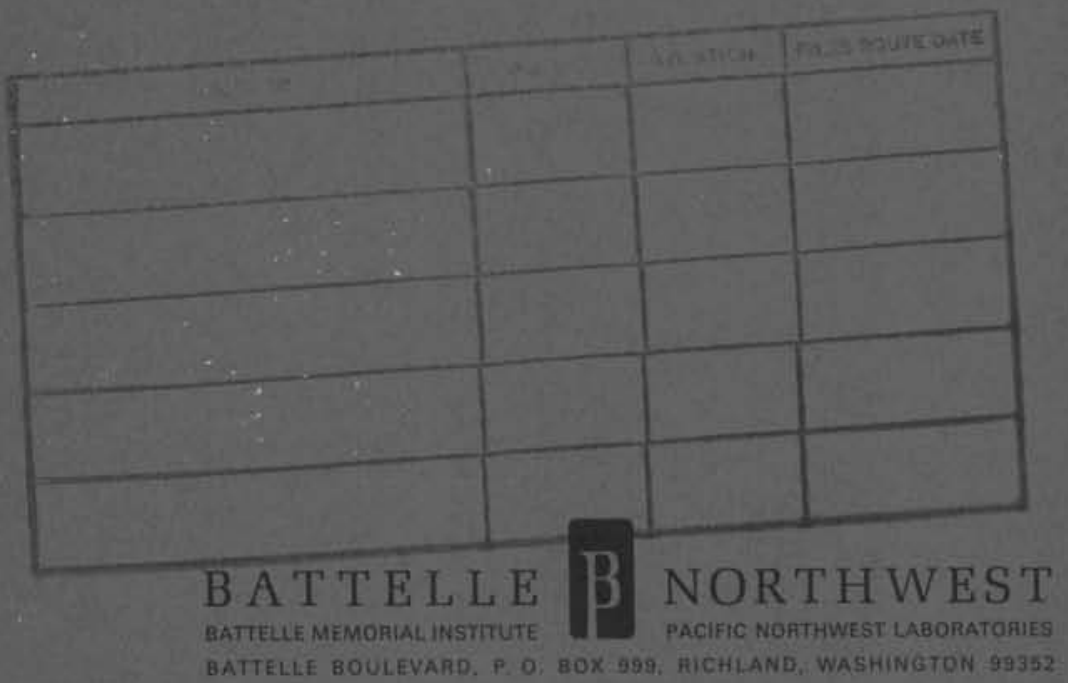




\section{LEGAL NOTICE}

This report was prepared as an account of Government sponsored work. Neither the United States, nor the Commission, nor any persan acting on beholf of the Commission:

A. Makes any warranty or representation, expressed or implied, with respect to the accuracy, com. pleteness, or usefulness of the information contained in this report, or that the use of any information, apparatus, method, or process disclosed in this report may not infringe privately owned rights; or

B. Assumes any liabilities with respect to the use of, or for damages resulting from the use af any information, apporalus, method, or process disclosed in this report.

As used in the above, "person acting on behalf of the Commission" inctudes any employee or contractor of the Commission, or employee of such contractor, to the extent that such employee or contractor of the Commission, or employee of such contractor prepares, disseminates, or provides access to. any information pursuant to his employment of contract with the Commission, or his employment with such contractor.

\section{PACIFIC NORTHWEST LABORATORY \\ RICHLAND, WASHINGTON \\ operaled by}

BATTELLE MEMORIAL INSTITUTE

for the

UNITED STATES ATOMIC ENERGY COMMISSION UNDER CONTRACT AT(45-1)-1830 


\author{
BNWL - 1324 \\ UC-80, Reactor Technology \\ CALCULATIONS OF BURNUP AND DAMAGE \\ FOR FAST REACTOR FUELS \\ by \\ R. E. Dahl, J r \\ Metallurgy and Ceramics Department \\ Chemistry and Metallurgy Division
}

April 1970 
BNWL- 1324

Printed in the United States of America Available from

Clearinghouse for Federal Scientific and Technical Information National Bureau of Standards, U.S. Department of Commerce Springfield, Virginia 22151

Price: Printed Copy $\$ 3.00 ;$ Microfiche $\$ 0.65$ 


\title{
CALCULATIONS OF BURNUP AND DAMAGE FOR FAST REACTOR FUELS \\ R. E. Dahl, Jr.
}

\begin{abstract}
$\underline{\text { ABSTRACT }}$
A method has been developed for relating burnup in fast reactor fuels to the damage sustained by the cladding. Traditionally, data on structural materials irradiation tests are reported in units of fluence while fuels irradiation data and design requirements are in terms of burnup. The relationship between these systems must be determined so that the properties of the cladding can be predicted accurately for LMFBR fuels. These analyses show that the cladding to burnup ratio depends in a complex manner upon the initial fuel composition, the neutron spectrum, and the duration of the irradiation. Moreover, the conditions in an IMFBR cannot be duplicated in any test reactor. Therefore, analyses are required in both the application of test irradiation data to LMFBR fuel design and in the selection of irradiation facilities. Problems on the loss of pin power during extended irradiations and uncertainties in conventional burnup measurements are discussed.
\end{abstract}




\section{CONTENTS}

\begin{tabular}{|c|c|c|c|c|c|c|c|c|c|c|c|}
\hline INTRODUCTION. & - & - & $\cdot$ & - & - & - & - & - & $\cdot$ & - & 1 \\
\hline METHOD OF ANALYS & & . & - & - & • & - & $\cdot$ & • & - & . & 3 \\
\hline DAMAGE & - & - & - & • & - & - & $\cdot$ & $\cdot$ & • & - & 6 \\
\hline DISCUSSION & $\cdot$ & • & - & - & - & - & - & - & • & 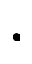 & 12 \\
\hline Cladding Damag & e to & & urnup I & Rati & & - & - & . & $\cdot$ & 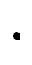 & 12 \\
\hline Effect of Bu. & rnup & & - & - & - & - & - & - & - & - & 13 \\
\hline Effects of E & nric & $\mathrm{hm}$ & ent & . & - & - & - & - & $\theta^{\prime}$ & $\theta^{\circ}$ & 13 \\
\hline Effects of $N$ & Jeutr & & Spect 1 & $\mathrm{ra}$ & . & - & . & - & $\bullet$ & $\bullet$ & 16 \\
\hline Burnup Measure & ment & & . & - & - & - & - & - & $\theta^{\circ}$ & 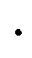 & 16 \\
\hline FISSION ENERGY & . & • & - & - & - & . & . & - & - & • & 20 \\
\hline Fuel Compositi & on & $\cdot$ & - & - & • & • & • & - & • & ${ }^{\circ}$ & 21 \\
\hline TEST DESIGN AND & ANAI & & SIS. & - & - & . & - & . & - & • & 21 \\
\hline SUMMARY . . & $\cdot$ & $\cdot$ & - & - & - & - & • & $\cdot$ & • & - & 22 \\
\hline ACKNOWLEDGMENIS & $\cdot$ & - & $\cdot$ & - & $\cdot$ & • & $\cdot$ & - & • & - & \\
\hline REFERENCES - & . & - & $\cdot$ & • & • & - & • & - & • & •" & \\
\hline DISTRIBUTION. & - & - & - & - & $\cdot$ & - & - & • & • & $\cdot$ & Distr- \\
\hline
\end{tabular}


BNWL -1324

\section{LIST OF FIGURES}

1 Steps in Correlation of Burnup and Cladding Damage 4

2 Nuclear Reactions Included in Burnup Calculations 5

3 Energy-Dependent Cross Sections for Fission Reactions and Damage Production

4 Neutron spectra, EBR-II Row 3 - FTR Driver

5 Response of Fission and "Damage" Reactions, EBR-II - ROW 3

6 Response of Fission and "Damage" Reactions, FTR Driver-I

7 FTR Driver-I Vert. Core; $\mathrm{R}=14.3, \mathrm{Z}=1.14 \quad 14$

8 FTR Driver-I Vert. Core; $\mathrm{R}=14.3, \mathrm{Z}=1.14 \quad 18$

9 FTR Driver-I Vert. Core; $\mathrm{R}=14.3, \mathrm{Z}=1.14$ 


\title{
CALCULATIONS OF BURNUP AND DAMAGE FOR FAST REACTOR FUELS
}

\author{
R. E. Dahl, J r.
}

\section{INTRODUCTION}

The behavior of fuel elements during irradiation must be accurately predicted and measured to optimize fuel element design for safe and economic operation of fast breeder reactors. The correlation between burnup and cladding damage is particularly important in fast reactor fuels since the fuel elements must be irradiated to high burnups for economic feasibility. A very high fluence of neutrons is sustained during these extended irradiations that cause cladding damage, such as swelling or loss of strength, which could limit fuel element life and fuel cycle duration. Traditionally, data on fuels irradiation experiments and design criteria for fuel elements have been reported as MWd/tonne, while irradiation effects on cladding materials are reported as fast fluence (e.g., $\phi$ t $\mathrm{E}>0.1 \mathrm{MeV}, \mathrm{E}>1 \mathrm{MeV})$. Relationships between these reporting systems must be established to quantitatively estimate the irradiation-induced property changes in fuel cladding and to apply irradiation test data to fuel cladding design.

Fuels and materials irradiation experiments are being conducted in metal-fueled reactors, such as the EBR-II and the Dounreay Fast Reactor (DFR), which have relatively "hard" neutron spectra. The FTR and LMFBR's fuels which will be designed from these tests are to be ceramic oxide fuels which yield a much softer spectra. That is, the average neutron energy will be less, and the range of energy over which the neutron population is distributed will be greater. Since damage and fissions are caused according to energy dependent 
functions that vary substantially across the energy range of neutrons in a fast reactor spectrum, relationships between cladding and burnup differ among fast reactors according to neutron spectra. Thus, the damage-to-burnup ratio will differ widely among the facilities used for testing fuels and the reactors for which the fuels are being developed.

Optimization of fuel element design for fast reactors requires an estimate of the reduction in heat generation in a fuel element during irradiation to high burnup. In the mixed oxide $\left(\mathrm{PuO}_{2}\right.$ and $\left.\mathrm{UO}_{2}\right)$ fuels planned for the FIR and LMBFR's, there are a variety of fissile and fertile isotopes. Each of these isotopes has a different energy-dependent cross section, therefore, their rates of growth, fission, and depletion will differ in each spectra and will have a different time dependence. The analysis of fuel irradiation data and fuel element design must incorporate a detailed determination of the nuclear environment and computation of irradiation effects in both the fuel and cladding.

To determine the scope and magnitude of uncertainties encountered in relating damage to burnup, this report presents the results of analyses of "typical" tests to develop FTR fuels. Nominal fuel compositions and neutron spectra for the irradiation facilities were used. Presently, a 11 BNW tests conducted for FTR fuels development are being analyzed on a pin by pin basis in the manner described in this report. Data from such an analysis define the relationships among burnup, fluence, and cladding damage in the irradiation tests used in the development of FTR fuels; assist in developing correct burnup measurement techniques; and provide a basis for optimizing fuel testing programs by calculation of heat generation, burnup, power, cladding damage, and other parameters of fuel performance, so that safety and test criteria can be satisfied. 


\section{METHOD OF ANALYSIS}

The data reported in this paper were generated using the program BIPPY, which is described in detail in Reference 1. Since that report includes a derivation of equations included in the analysis and the flow of logic employed, only a very brief summary of the analytical method is given here.

The steps recommended for analysis of fast reactor fuels are shown in Figure 1. The first step, the determination of the neutron spectrum, can be done through reactor physics analyses (e.g., diffusion theory, transport theory, or Monte Carlo) or experimental measurements (e.g., multiple foils, neutron spectrometry, or time of flight). That spectrum is then used to obtain spectral averaged cross sections for the fission and transmutation of the fissile and fertile isotopes in the fuel as well as neutron scattering and absorption by the elements in the cladding, such as iron, nickel, and chromium.

Spectral averaged cross sections, flux levels, mechanical design of the fuel element, and original isotopic concentrations constitute the necessary input (to BIPPY) that is to be used in the next step of the analysis. The isotopic concentrations (Figure 2) computed in BIPPY include ${ }^{235} \mathrm{U}, 238_{\mathrm{U}}$, ${ }^{239} \mathrm{Pu},{ }^{240} \mathrm{Pu}$, and ${ }^{241} \mathrm{Pu}$. The concentrations at each time step are calculated through a series of Batemen-type equations. When the concentration and the fission rates of the fissile isotopes are determined, burnup, specific power, heat generation, and cladding damage can be calculated.

Burnup rates are calculated and integrated over time through a numerical analysis technique developed for this code to obtain the total burnup. Data may be calculated for any specified burnup increments up to a target burnup. For this 


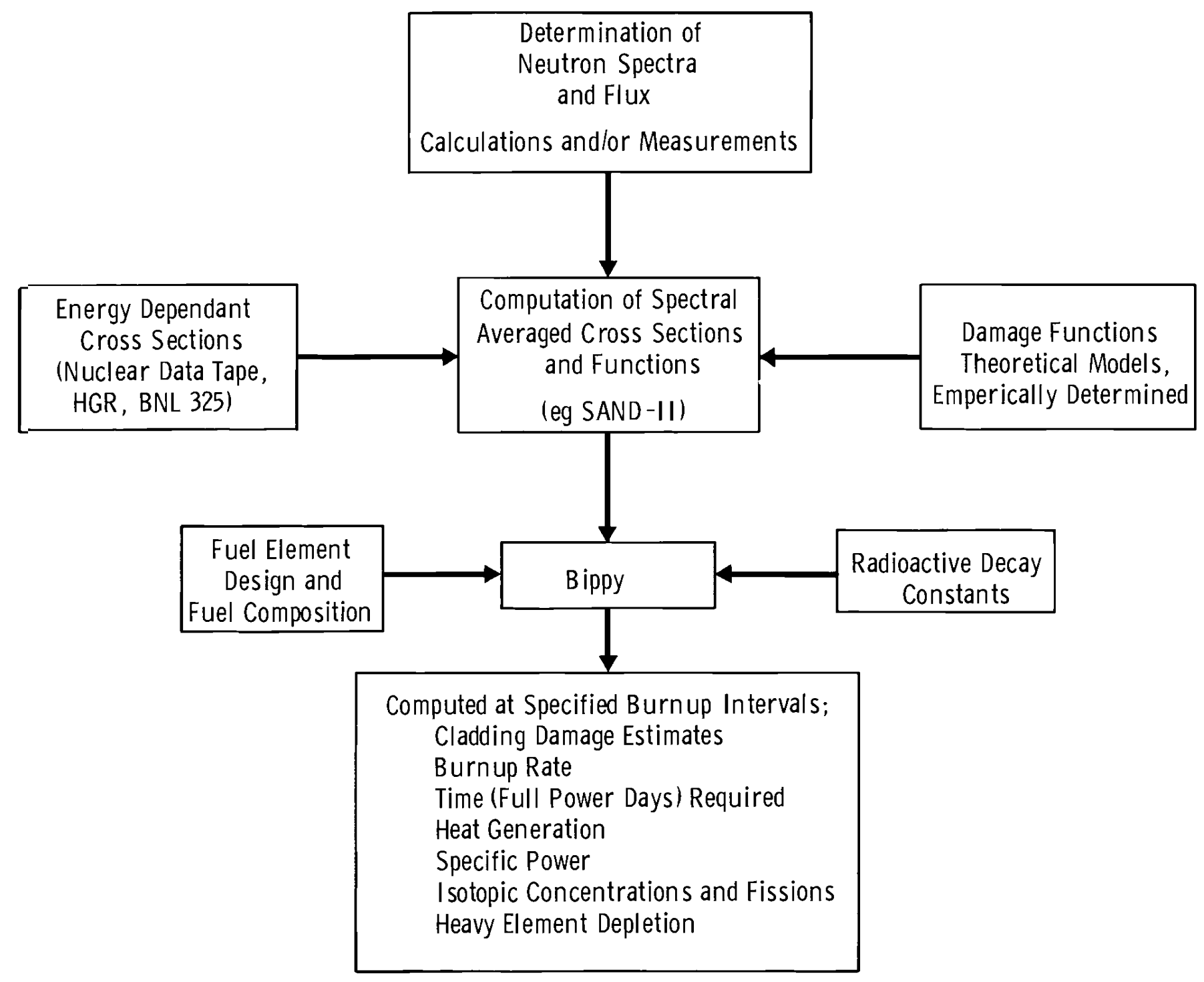

Neg 700939

FIGURE 1. Steps in Correlation of Burnup and Cladding Damage 

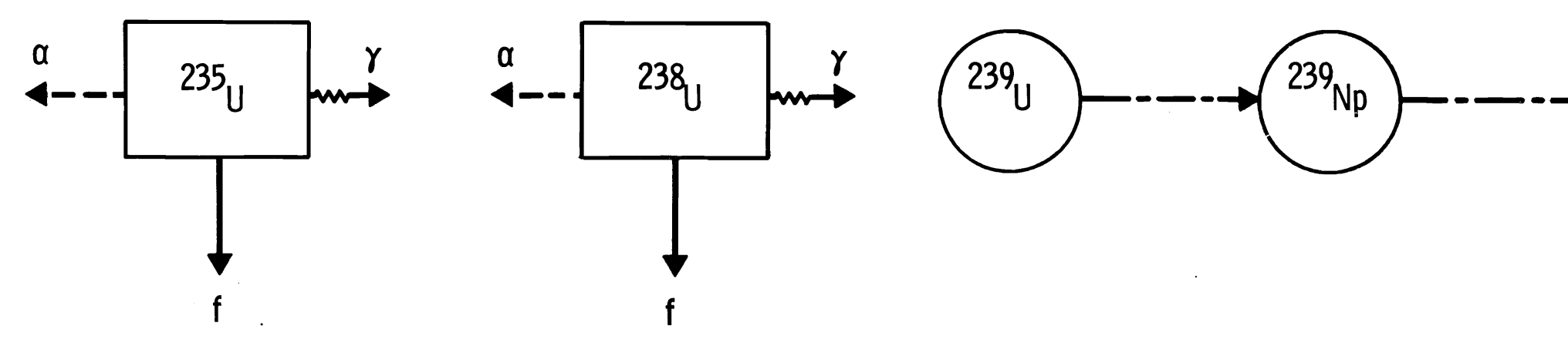

$\longrightarrow$ Fission $(n, f)$

$\longrightarrow \longrightarrow \alpha$ Decay

$\longrightarrow$ Neutron Capture $(n, \gamma)$

$\longrightarrow-\beta^{-}$Decay

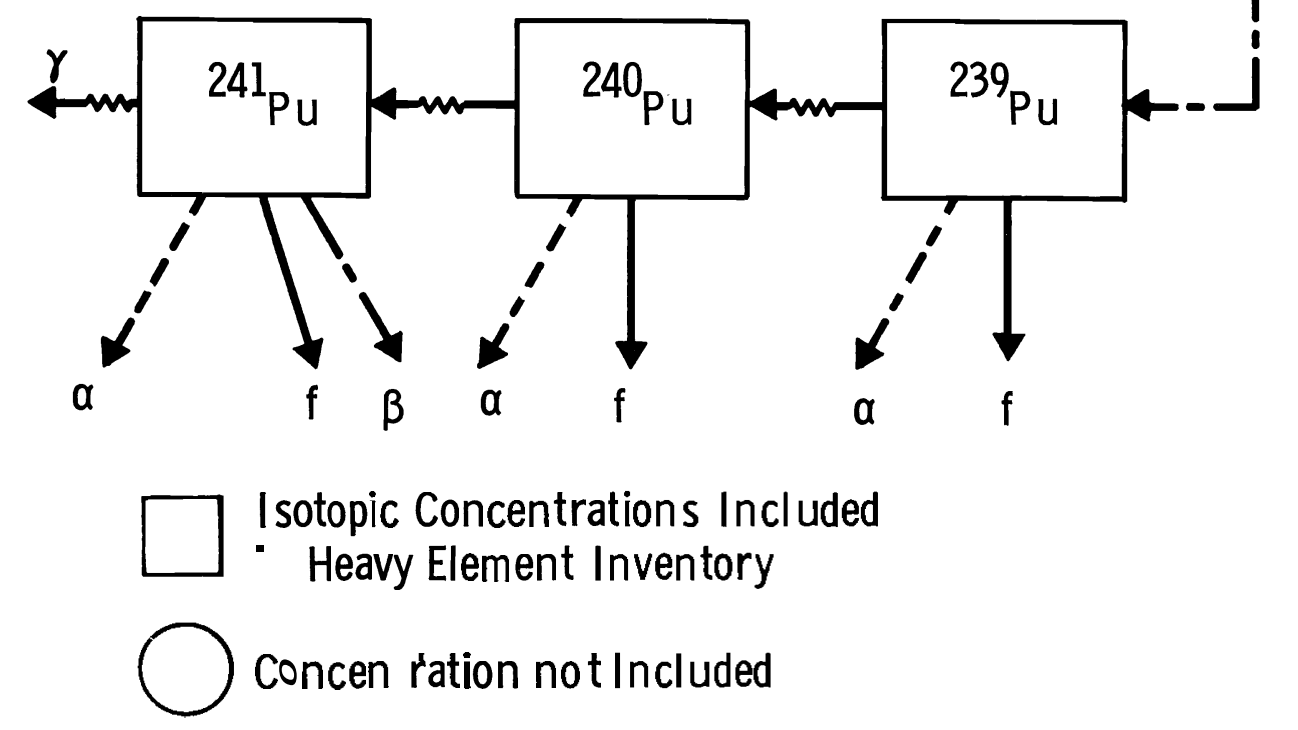

Neg 0692131-1

FIGURE 2 Nuclear Reactions Included in Burnup Calculations 
particular study, data were calculated at every $1000 \mathrm{MWd} /$ tonne up to 100,000 MWd/tonne. Among the data calculated are the concentration and fission rate of each heavy element isotope, the specific power in $W / g$, the lineal heat generation for the fuel pin in units of $\mathrm{kW} / \mathrm{ft}$, the fluence of neutrons with energies greater than $0.1 \mathrm{MeV}$, the total neutron fluence, the full power days required to reach specified burnup, cladding damage according to some 5 different theoretical or empirical models, and the concentration of any 10 fission products at every burnup interval. In order to facilitate understanding and interpretation of the data, a routine was developed to plot all of the parameters, either as a function of time or burnup.

\section{DAMAGE}

Cladding damage is a function of many variables (e.g., material parameters such as impurity level, cold work, etc.) and others such as the irradiation temperature and nuclear environment. This analysis was made to provide a basis for correlation of data from one reactor to another. Therefore, an implicit assumption in these analyses is that a 11 variables, other than neutron flux and spectrum, are constant among the irradiations to be correlated. Actually stress and temperature vary among tests and during the same test, but the variations occur within a relatively narrow range so test data can be adequately inter-related by assuming these variables to be constant. In order to correlate data between different reactors, an energy-dependent model is determined, or postulated, to calculate damage production, since "damage" is the change of some physical or mechanical property of interest. Of these models, the clustered vacancies model is recommended for correlation of cladding swelling. Since voids presumably nucleate on large vacancy clusters and grow by condensation of vacancies upon these clusters, this model developed by Russcher ${ }^{(2)}$ should be the most correct. 
The clustered vacancy numbers are the number of vacancies, which are associated with clusters of seven or more vacancies, produced in displacement cascades during irradiation. The average number of vacancies per cluster is 12 , so the cluster concentration would be $1 / 12$ of the numbers appearing in Table 1 and would be defined in units of clusters $/ \mathrm{cm}^{3}$.

Total displacements according to the Thompson-Wright model as modified by Beeler $(3)$ is also used to correlate irradiation damage. The displacement normalization, however, will presumably be less accurate than the clustered vacancy model in correlating swelling of cladding. Fluence $\mathrm{E}>0.1 \mathrm{MeV}$ is calculated and presented, since much of the data for structural materials irradiated in fast reactors are normalized on this basis, which is thought to correlate cladding damage between the FTR and EBR-II within about 25\% accuracy. The clustered vacancy model is probably the most accurate correlation basis; however the differences between using it and using the fluence of neutrons with energies greater than $0.1 \mathrm{MeV}$ are only about $18 \%$

As data become available on swelling of structural materials and dilation of fuel elements caused by fast reactor irradiations, damage models will be developed using the unfolding technique. (4) These empirically based models should substantially refine the correlation and prediction of irradiation effects in fast reactor materials.

Energy-dependent cross sections for damage, based on the displacement and clustered vacancy models and the fission cross sections, are presented in Figure 3. The extremes in neutron spectra among irradiation facilities considered in this analysis (EBR-II, Row 3, and the FTR ${ }^{(5)}$ ) are presented in Figure 4. Response functions [i.e., the product of $\phi(E)$ and $G(E)]$ for these spectra are presented in Figures 5 and 6 . 
TABLE 1. Cladding Fluence versus Burnup and E̊richment in FTR Spectra and Fuel Test Facilities in Damage Correlation wases

\begin{tabular}{|c|c|c|c|c|c|c|c|c|c|c|c|c|c|}
\hline \multirow[b]{2}{*}{ Reactor } & \multirow{2}{*}{$\begin{array}{c}\text { Uranium * } \\
\text { Enrichment }\left(\% 235_{U}\right) \\
\end{array}$} & \multicolumn{4}{|c|}{$\phi \mathrm{t} \mathrm{E} 0.1 \mathrm{MeV} \times 10^{-23}$} & \multicolumn{4}{|c|}{ Total Displacements $\times 10^{-23}$} & \multicolumn{4}{|c|}{ Clustered Vacancies $\times 10^{2} \mathrm{~N} \geq$} \\
\hline & & 20,000 & 40,000 & 60,000 & $\underline{80,000}$ & 20,000 & 40,000 & 60,000 & 80,000 & 20,000 & 40,000 & 60,000 & $8 \overline{0,000}$ \\
\hline EBR-I I & Natural $(0.7)$ & 0.409 & 0.841 & 1.30 & 1.78 & 1.98 & 4.07 & 6.27 & 8.59 & 0.821 & 1.67 & 2.57 & 3.53 \\
\hline \multirow[t]{3}{*}{ Row 3} & $27 \%$ & 0.267 & 0.545 & 0.836 & 1.14 & 1.29 & 2.64 & 4.05 & 5.52 & 0.530 & 1.08 & 1.66 & 2.27 \\
\hline & $45 \%$ & 0.215 & 0.438 & 0.670 & 0.911 & 1.04 & 2.12 & 3.24 & 4.41 & 0.427 & 0.870 & 1.33 & 1.81 \\
\hline & $93 \%$ & 0.141 & 0.287 & 0.436 & 0.590 & 0.684 & 1.39 & 2.11 & 2.85 & 0.281 & 0.570 & 0.867 & 1.17 \\
\hline \multirow[t]{4}{*}{ FTR Ilriver } & Natural $(0.7)$ & 0.293 & 0.602 & 0.929 & 1.27 & 1.24 & 2.56 & 3.95 & 5.41 & 0.510 & 1.02 & 1.58 & 2.16 \\
\hline & $27 \%$ & 0.165 & 0.339 & 0.523 & 0.716 & 0.703 & 1.44 & 2.21 & 3.04 & $0.2: 1$ & 0.576 & 0.887 & 1.22 \\
\hline & $45 \%$ & 0.127 & (). 260 & 0.399 & 0.544 & 0.540 & 1.10 & 1.69 & 2.30 & 0.26 & 0.441 & 0.676 & 0.923 \\
\hline & $93 \%$ & 0.078 & 0.159 & 0.243 & 0.329 & 0.333 & 0.677 & 1.03 & 1.40 & 0.13 & 0.270 & 0.412 & 0.557 \\
\hline \multirow[t]{4}{*}{ FTR/EBR-II } & Natural & 0.716 & & & & 0.626 & 0.629 & 0.630 & 0.630 & 0.609 & 0.611 & 0.616 & 0.612 \\
\hline & $27 \%$ & 0.623 & \multirow{3}{*}{\multicolumn{3}{|c|}{$\begin{array}{l}\text { Nearly constant with } \\
\text { increasing burnup. }\end{array}$}} & 0.545 & 0.545 & 0.546 & 0.551 & 0.530 & 0.533 & 0.534 & 0.537 \\
\hline & $45 \%$ & 0.590 & & & & 0.519 & 0.519 & 0.522 & 0.522 & 0.506 & 0.507 & 0.508 & 0.510 \\
\hline & $93 \%$ & 0.553 & & & & 0.487 & 0.487 & 0.488 & 0.491 & 0.473 & 0.474 & 0.475 & 0.476 \\
\hline
\end{tabular}




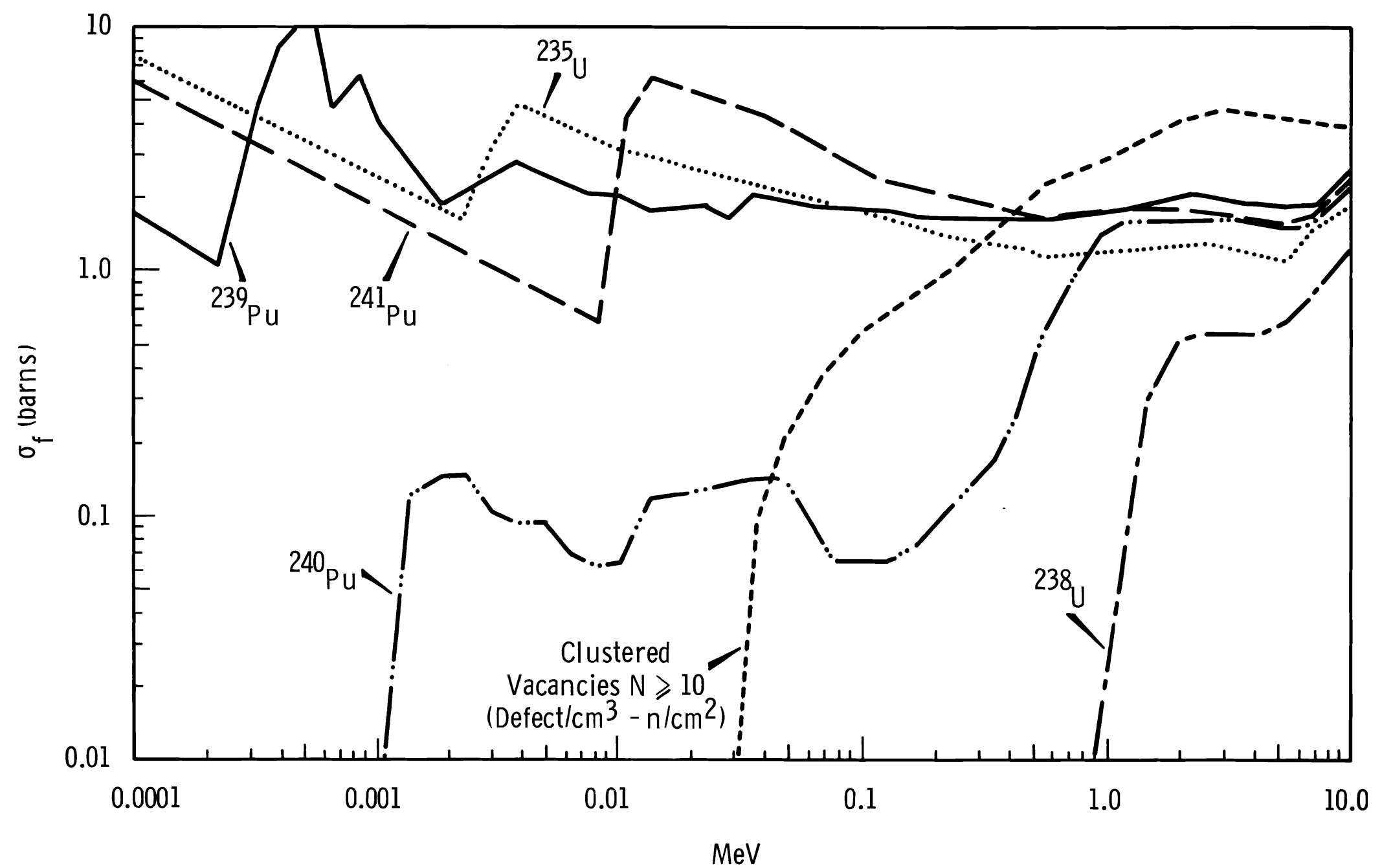

Neg 0692131-14

FIGURE 3. Energy-Dependent Cross Sections for Fission Reactions and Damage Production 


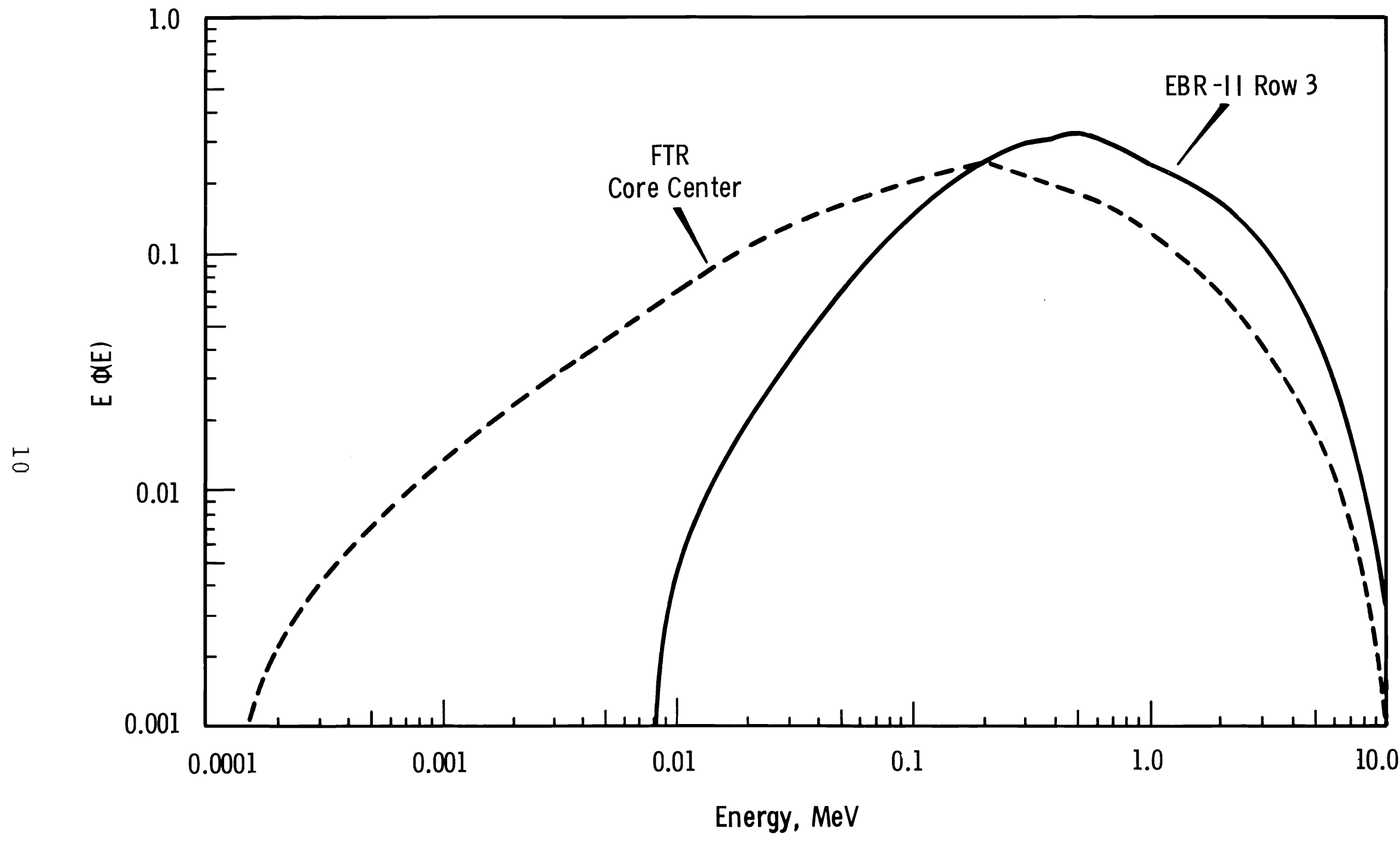

Neg $0692131-7$

FIGURE 4 Neutron Spectra, EBR-II Row 3 - FTR Driver 


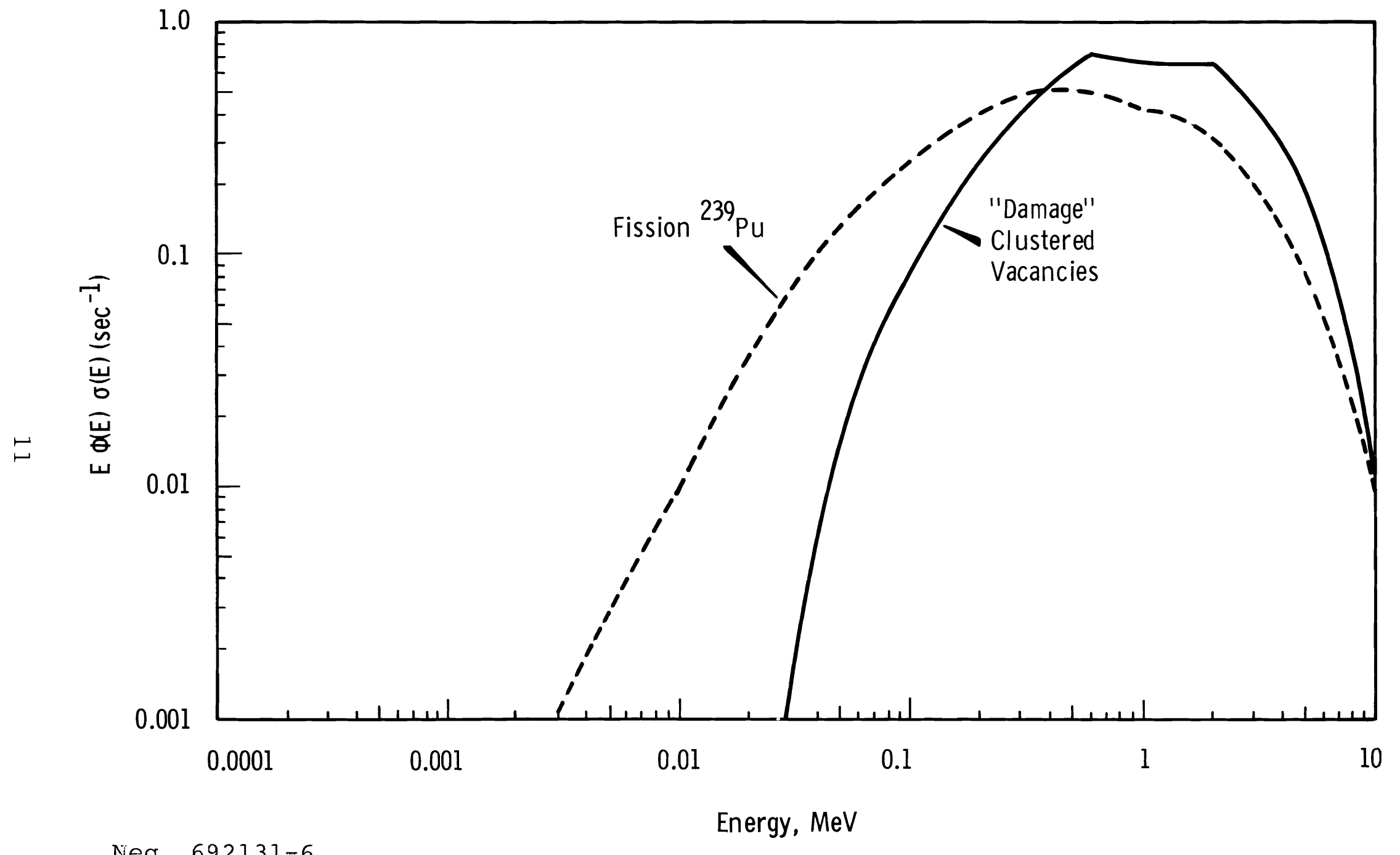

Neg 692131-6 


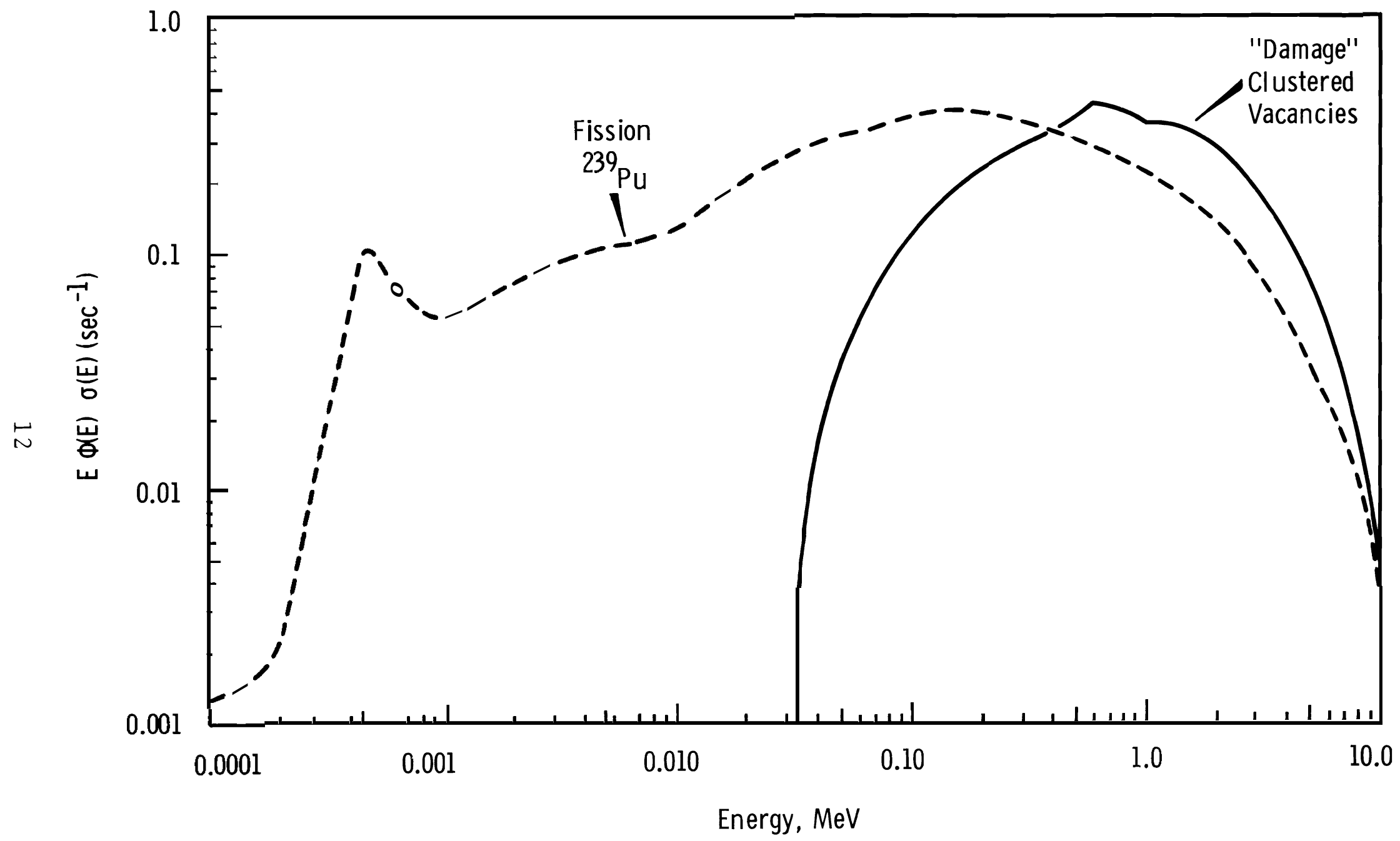

Neg $0692131-5$

FIGURE 6. Response of Fission and "Damage" Reactions, FTR Driver-I 
The response functions show that in the EBR-II spectrum, the neutrons that cause fissions also damage the cladding, while in the FIR the neutrons causing the fissions will have substantially lower energy than the neutrons generating most of the displacements. Therefore, the relationship between cladding damage and burnup will differ greatly between these two reactor spectra. In the FTR a high burnup could be obtained with relatively less cladding damage than in the EBR-II.

Damage models were used to estimate the total number of displacements, the concentration of vacancies associated with clusters of 7 or more vacancies each, and the number of vacancies associated with clusters having 10 or more vacancies. These models are based on theoretical analysis. Russcher's (2) method was used to calculate group averaged values for these models.

"Damage" was calculated according to several models, which are used to correlate damage to structural materials. These are: the total neutron fluence, which includes neutrons of all energies; the fluence of neutrons whose energies exceed $0.1 \mathrm{MeV}$, the total number of displacements produced during irradiation, and the number of vacancies produced during irradiation, which are associated with large vacancy clusters.

\section{DISCUSSION}

\section{CLADDING DAMAGE TO BURNUP RATIO}

The relationship, or ratio, between cladding damage and burnup depends upon the interaction of several factors. These include the burnup in the fuel element, the enrichment and composition of the fuel, and the neutron spectrum. Since each of these factors also affects the heat generation of an element, design and interpretation of a fuel irradiation test becomes complex. 
BNWL -1324

\section{Effect of Burnup}

The relationship between burnup and cladding damage for a fuel element will not remain constant during irradiation. Generally the flux and spectra do not vary significantly with time, but as the concentration of fertile atoms decreases, the fission rate and consequently the burnup rate decrease. However, the rate of cladding damage remains constant since it depends upon the reactor flux and spectra, which are essentially constant over a long time. Therefore, the damage to burnup ratio increases with time, or burnup. As an example, the damage curve for an FIR driver fuel element, solid curve in Figure 7, lies above that which would be estimated by an extrapolation of the initial damage to burnup ratio, the dashed curve superimposed in Figure 7. The damaging fluence $(\phi E>0.1 \mathrm{MeV})$ is about $25 \%$ greater at 100,000 MWd/tonne than the extrapolated value.

\section{Effects of Enrichment}

The fission rate of uranium fuels is generally proportional to their ${ }^{235}$ U enrichment. Since the burnup rate is greater for more highly enriched fuels, the time required to achieve target burnup is decreased. Consequently, the cladding damage is less because the fluence is less. Enrichment is much more effective in softer spectra because the fission cross sections of ${ }^{235_{\mathrm{U}}}$ and ${ }^{239} \mathrm{Pu}$ are greater at the lower energies. Thus, the effects of enrichment on the damage to fluence ratio in $75 \% \mathrm{UO}_{2}-25 \% \mathrm{PuO}_{2}$ fuels are 1 ess in the EBR-II than in the FTR. Data for several fuels with varied enrichment, irradiated in the same flux and spectrum, are presented in Table 1 , where also damage to burnup ratios in the FIR are compared to those in an EBR-II test. The ratios show (according to all of the models) that damage in FIR fuels is about $60 \%$ of that for comparable fuels irradiated in the EBR-II. The ratios are nearly constant for increasing burnup. 


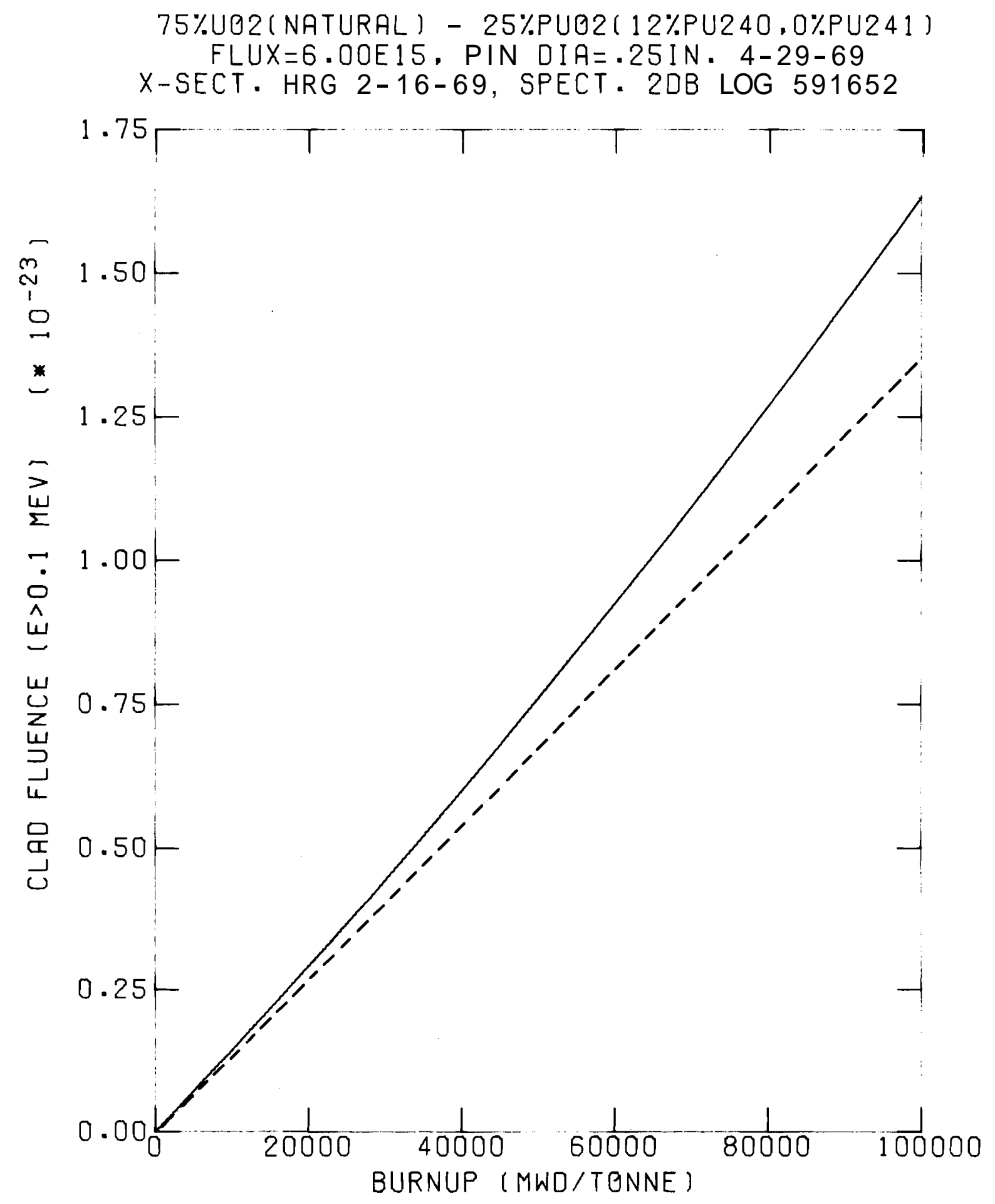

Neg $0692131-22$

FIGURE 7. FTR Driver - I Vert. Core; $R=14.3, \quad Z=1.14$ 
BNWL -1324

Effects of Neutron Spectra

Spectra affect damage to burnup relationships in that the fission cross sections and the damage functions are energy dependent. Damage rates are greater in harder spectra since the high energy neutrons are more effective in producing damage. On the other hand, fission rates are lower in harder spectra since fission cross sections (i.e., ${ }^{239} \mathrm{Pu}$ and ${ }^{235} \mathrm{U}$ ) are somewhat inversely dependent on neutron energy. Quite different spectra occur in the irradiation facilities used to develop FIR fuels. The FIR and the EBR-II Row 3 irradiation positions represent extremes in neutron spectra and are chosen to illustrate the effects of spectra on burnup and damage correlation. The EBR-II is a metal fueled reactor that has a relatively "hard" spectrum. The FTR will have mixed oxide fuels and a much "softer" spectrum than that in the EBR-II core (Figure 2). Cladding damage calculated at 20, 40, 60 and 80 thousand MWd/tonne in the FTR and in the EBR-II are presented in Table 1. Note that the damage at any given burnup in the FTR for a fully enriched element is approximately $40 \%$ of that in the EBR-II. The softer FTR spectrum causes a higher fission rate, thus the damage to burnup ratio is less. The importance of high energy neutrons in the damage models is seen quite clearly in studying the ratio of calculated damage from irradiations in the FIR to actual damage from irradiations in EBR-II Row 3. The cladding of an FTR fuel element (natural uranium) should be damaged only about $50 \%$ as much as the cladding of an element irradiated in the EBR-II Row 3, because it is exposed to a lower fluence of high energy neutrons.

BURNUP MEASUREMENTS

Burnup is generally determined by measuring the concentration of ${ }^{148} \mathrm{Nd}$ in a fuel pin after irradiation. The number of fission events that occurred is calculated using an assumed 
average fission yield for ${ }^{148} \mathrm{Nd}$. Fast reactor fuels are a mixture of both plutonium and uranium, and contain several fissile and fertile isotopes. Each of these isotopes has a rate of growth, fission, and transmutation, which depends differently on the neutron spectrum and flux. Therefore, there is a unique relation between a fission product concentration and burnup for each fuel pin and for every irradiation. Differences can be large enough to cause unacceptable error in burnup measurement. For example see Figures 8 and 9, which show the isotopic concentrations and isotopic fission rates for the FTR driver fuel containing natural uranium. The relative concentrations of each of the isotopes and the percentage of the total fissions that each contributes vary as a function of time and neutron spectrum. The yield of ${ }^{148} \mathrm{Nd}$ atoms per fission is substantially different for each of the fissile and fertile isotopes. Hence, accurate computation of the total number of fission events from the concentration of the fission product (i.e., ${ }^{148} \mathrm{Nd}$ ) requires an estimation of the fissions contributed by each particular isotope. Therefore, a knowledge of the neutron spectrum, flux, and fuel concentrations is required for an accurate calculation of the fuel burnup.

Fission yield values for thermal neutron-induced fission of $235 \mathrm{U}$-if used in the analysis of a fast reactor burnup at target burnups greater than 50,000 MWd/tonne--would cause errors of approximately 20 to $30 \%$. Cumulative yields based on measurements for fast neutron-induced fission, such as those compiled by Meek and Rider, (6) are recommended.

A common assumption in burnup analyses is that the ${ }^{238} \mathrm{U}$ concentration is invariant. This is in error for fast reactor irradiations and particularly so for those conducted in the EBR-II to a high target burnup, since the ${ }^{238} \mathrm{U}$ is depleted about 15\% at 50,000 MWd/tonne. 


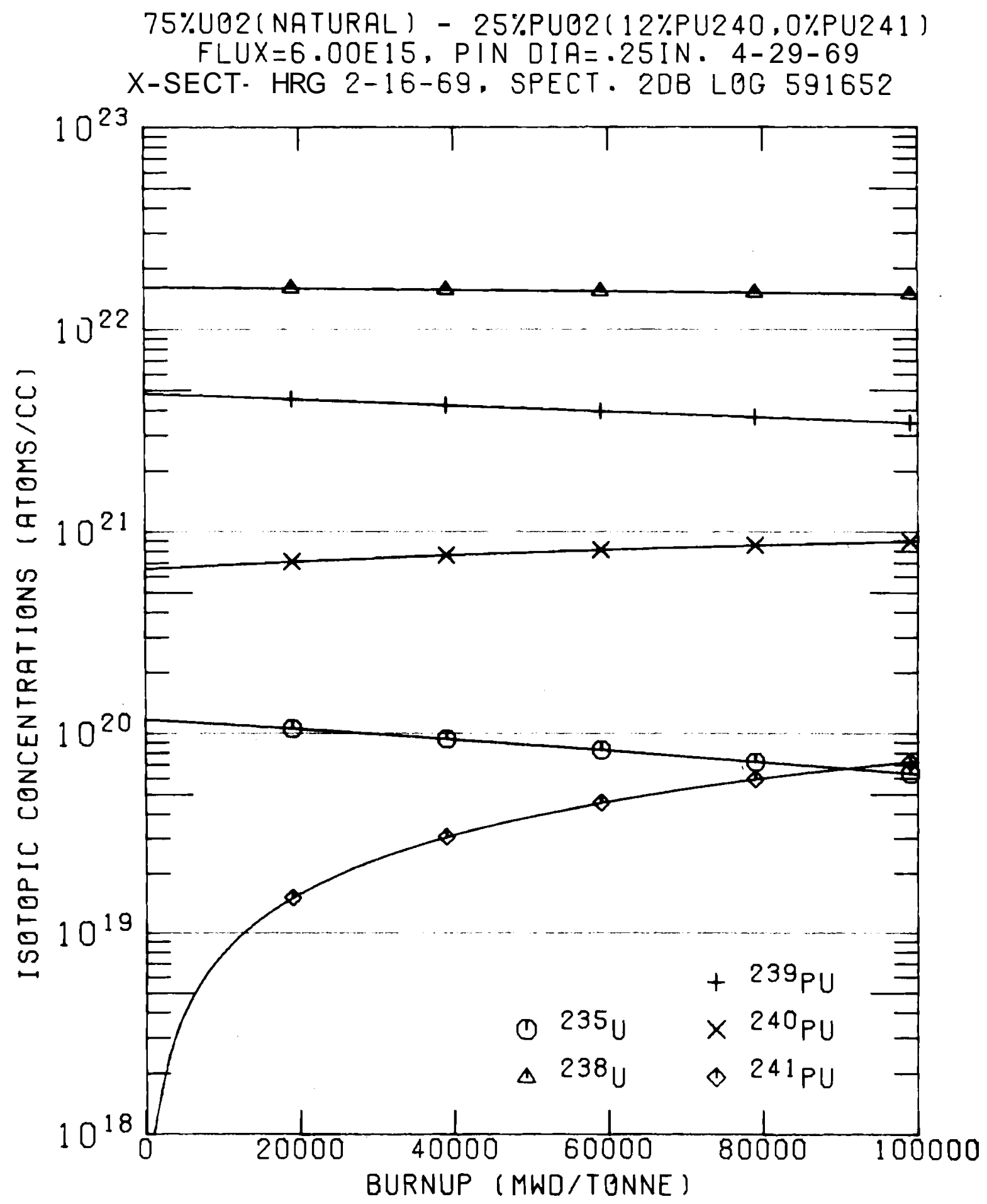

Neg 0692131-21

FIGURE 8. FTR Driver-I Vert. Core; $R=14.3, Z=1.14$ 


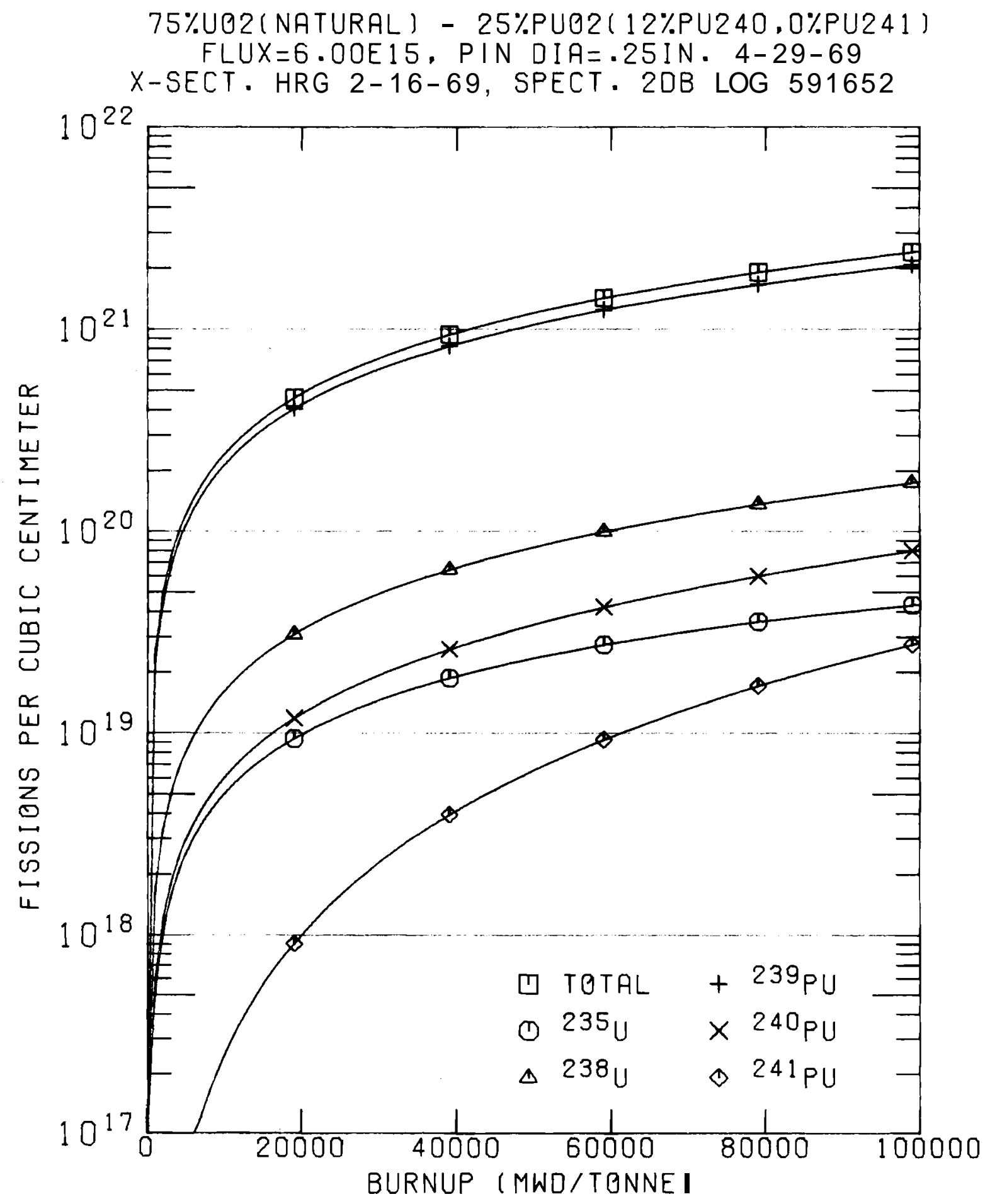

Neg 0692131-20

FIGURE 9. FTR Driver-I Vert. Core; $R=14.3, \quad z=1.14$ 
Burnup is often estimated by assuming that the heavy element depletion is approximately 1 at.\% per 10,000 MWd in fast reactors. Actually, the atom percent depletion on "burnout" also depends on the fuel composition and the neutron spectrum and can vary substantially among fast fuel tests. The ratio of the macroscopic absorption cross section to the fission cross section (i.e., $\Sigma_{a} / \Sigma_{f} \equiv$ a) for various fuels is a function of neutron energy. Burnup was found to vary between 0.78 at.\% and $\mathbf{1 . 1}$ at.\% per 10,000 MWd in the fuel tests studied. This is a difference of about $30 \%$.

\section{FISSION ENERGY}

Uncertainties and inconsistencies arise in fuel analyses because of differences in assumed fission energies. Values of fission energy used in analyses range between $175 \mathrm{MeV}$ per fission and $215 \mathrm{MeV}$ per fission, This has a large effect on calculations of atom percent depletion and estimates of the rate of heat production.

Results of computations of heavy element depletion depend on the fission energy assumed, since the duration of an irradiation is computed in terms of MWd, the unit of heat generation. If a large value is assumed for the fission energy, fewer fissions are calculated to generate a given amount of heat, and target burnups would be achieved in less time. Consequently, less heavy element depletion would be computed than if a lower value of fission energy was assumed.

In analysis of fuels, uncertainties as to the proper value for fission energy arise not only from nuclear physics considerations, but also because most fast reactor irradiations are conducted in areas of reactors where the heat and energy flows to a fuel pin are not isotropic. Of approximately $200 \mathrm{MeV}$ of energy released for each ${ }^{235} \mathrm{U}$ fission, approximately $20 \mathrm{MEV}$ 
are associated with fission gammas. This energy is deposited outside of the fuel pin in which it was generated. If irradiations were performed at positions where the photon current was isotropic, a value of about $200 \mathrm{MeV}$ per fission would be correct, since energy lost by the fuel element would be regained by the absorption of photons generated in other fuel pins. In most fast reactor irradiations, however, this is not a valid assumption, since the reactor cores are small leading to a definite outward photon current. A sizable fraction of the energy associated with fission gammas escapes from the core. Therefore, values assumed for fission energy should be less than the total fission energy, perhaps between 175 and $200 \mathrm{MeV}$. The exact value would depend upon the location of the fuel pin. The uncertainties would affect the predicted heat generation of a fuel element by up to $12 \%$. Reduction of this uncertainty is important in optimizing fuel tests and could possibly be accomplished by photon transport calculations for fast reactor cores.

\section{FUEL COMPOSITION}

Fuel compositions considered for the FIR range from 70 to $80 \% \mathrm{UO}_{2}$ with the remainder $\mathrm{PuO}_{2}$. As these fuels are irradiated, the rate of plutonium burnup is much higher than that of uranium burnup. Consequently, the plutonium to uranium ratio is substantially diminished. For example, during the irradiation of a $75 \%$ natural $\mathrm{UO}_{2}-25 \% \mathrm{PuO}_{2}$ element in the FTR to $80,000 \mathrm{MWd} /$ tonne, the percentage of $\mathrm{PuO}_{2}$ is reduced from $25 \%$ to $17 \%$. The properties of this material, such as density and thermal conductivity, could differ from those of the original fue 1 .

\section{TEST DESIGN AND ANALYSIS}

Perhaps the most critical consideration in the design of a fuel irradiation test is an accurate knowledge of the 
heat generation. The safety of the test as well as the usefulness of the test data depend upon accurate calculation of the lineal heat generation. Heat generation decreases with decreasing concentration of fissile isotopes, so a substantial reduction takes place during an extended irradiation. A loss of about 3\% per 60-day cycle was calculated for an FTR spectra and flux. The total loss was about $21 \%$ during an irradiation to $80,000 \mathrm{MWd} /$ tonne. Similarly the decrease in heat generation for fuel pins of the prototype design irradiated in Row 3 of the EBR-II to $80,000 \mathrm{MWd} /$ tonne are $20.7 \%$ for natural uranium and $11.6 \%$ for a $93 \%$ enriched uranium in the $\mathrm{CO}_{2}$. It is apparent that a substantial reduction in pin power occurs during these irradiations and that this should be considered in the planning and design of fuel tests so that optimization of FTR fuel element design can be achieved.

Irradiation tests for development of FTR fuels are designed to approximate as closely as possible lineal heat generation $(\mathrm{kW} / \mathrm{ft}$ ) fuel composition, and cladding damage-to-burnup ratios of FTR driver elements. Attainment of all of these criteria in EBR-II tests is impossible in a single test. Although the initial heat generation can be made to coincide between test and service elements by enrichment of uranium, the cladding damage to burnup ratios will differ. Further, these ratios have been demonstrated to vary as a function of time as well as spectra. Hence, correlation and analysis of test data are essential for FTR fuel development. To achieve this, the nuclear environment for each test must be determined and calculations using BIPPY or a similar code must be performed.

\section{SUMMARY}

This study has demonstrated that an analysis of fuel element performance, which reduces uncertainties due to neutron flux and spectra, can be made. Further, heat generation, cladding damage-to-burnup ratios and burnup determinations can be 
estimated within $10 \%$ for most tests. Therefore, the errors incurred in applying the results of an irradiation test to the design of an element can be minimized and defined. Such analyses are necessary in high burnup fuels since the time variation in heavy element concentrations leads to large changes in all of the important properties of the fuel element.

\section{ACKNOWLEDGMENTS}

This work was performed for and under the sponsorship of the FFTF Fuel Department Fuels Evaluation Section. Fuel Element designs were supplied by L. A. Pember. The expertise and guidance of L. A. Pember on fuel element design and the interpretation of data from fuels irradiation test programs contributed greatly to the completion of this study. 


\section{REFERENCES}

1. R. E. Dahl and R. D. Bourquin. BIPPY, A Computer Code for the Correzation of Fuel Element Burnup and Cladding Damage, BNWL-1247. Battelie-Northwest, Richland, Washington. 1969,

2. G. E. Russcher. Calculated Damage Function for Determining Irradiation Effectiveness, BNWL-1093. Battelle-Northwest, Richland, Washington. 1969.

3. J. R. BeeZer, Jr. "Vacancy and Interstitial CZuster Production in Neutron-Irradiated a Iron," J. Appl. Phys., vol. 37, p. 3000. 1966.

4. W. N. MeElroy, R. E. Dahl, Jr., and C. Z. Serpan. "Damage Function and Data Correlation," Nuclear Applications, vol. 7, no. 6. November, 1969.

5. J. L. Jackson. Unpublished Data. BattelZe-Northwest, Richland, Washington.

6. M. E. Meek and B. F. Rider. Summaru off Fission Product Yields for $235 \mathrm{U}, 238 \mathrm{U}, 239_{\mathrm{Pu}}$, and $241 \mathrm{Pu}$ at Thermal, Fission Spectrum and $14 \mathrm{MeV}$ Neutron Energies, APED-5298-A. General Electric, Pleasanton, California, October 1, 1968. 


\section{DISTR IBUTION}

No. of

Copies

$\underline{\text { OFFSITE }}$

1
AEC Chicago Patent Group

G. H. Lee

$\underline{\text { AEC Division of Reactor Development and Technology }}$

M. Shaw, Director, RDT

Asst Dir for Nuclear Safety

Analysis \& Evaluation Br, RDT:NS

Environmental \& Sanitary Engrg Br, RDT :NS

Research \& Development Br, RDT;NS

Asst Dir for Plant Engrg, RDT

Facilities Br, RDT:PE

Components Br, RDT:PE

Instrumentation \& Control Br, RDT:PE

Liquid Metal Systems Br, RDT:PE

Asst Dir for Program Analysis, RDT

Asst Dir for Project Mgmt, RDT

Liquid Metals Projects Br, RDT:PM

FFTF Project Manager, RDT:PM (3)

Asst Dir for Reactor Engrg, RDT

Control Mechanisms Br, RDT :RE

Core Design B r, RDT:RE (2)

Fuel Engineering Br, RDT:RE

Fuel Handling B $r$, RDT:RE

Reactor Vessels Br, RDT:RE

Asst Dir for Reactor Tech, RDT

Coolant Chemistry Br, RDT:RT

Fuel Recycle Br, RDT:RT

Fuels \& Materials Br, RDT:RT (2)

Reactor Physics Br, RDT:RE

Special Technology Br, RDT:RT

Asst D ir for Engrg Standards, RDT

EBR-II Project Manager, RDT :PM

$\underline{\text { AEC Division of Technical Information Extension }}$

AEC Division of Technical Information Extension

US/UK Fast Reactor Exchange (12)

Euratom/US Fast Reactor Exchange (35)

AEC Idaho Operations Office

Nuclear Technology Division

C. W. Bills, Director

Distr-1 
No. of Copies

1

4

1

5

2

$\frac{\text { Babcock \& Wilcox Co }}{\text { Atomic Energy Divisior }}$

S. H. Esleeck

G. B. Garton

Bechtel Corporation

J. J. Teachnor

1

BNW Representative

R. M. Fleischman (ZPPR)

1

Combustion Engineering

1000 MWe Follow-On Study

W. P. Staker, Project Manager

1 Combustion Engineering

Chattanooga, Tennessee

Mrs. Nell Holder, Librarian 
No. of

Copies

5 General Electric Company

Advanced Products Operation

Karl Cohen (3)

Nuclear Systems Programs

D. H. Ahmann (2)

2 Gulf General Atomic Inc. General Atomic Division

D. Coburn

$1 \quad$ Idaho Nuclear Corporation

J. A. Buckham

1 Liquid Metal Information Center

A. E. Miller

1

Liquid Metal Engineering Center

R. W. Dickinson

1 Oak Ridge National Laboratory

W. O. Harms

1 Stanford University

Nuclear Division

Division of Mechanical Engrg

R. Sher

1 United Nuclear Corporation

Research and Engineering Center

R. F. DeAnge 1 is

15 Westinghouse Electric Corporation

Atomic Power Division

Advanced Reactor Systems

D. C. Spencer

\section{ONSITE-HANFORD}

AEC Chicago Patent Group

R. K. Sharp 
No. of

Copies

2

1

1

1

1

66

AEC Richland Operations Office

J. M. Shivley

Battelle Memorial Institute, Columbus

Bechtel Corporation

M. O. Rothwell (Richland)

RDT Asst Dir. for Pacific Northwest Programs

D. C. Spencer

Westinghouse Electric Corporation, Rich1and

J. D. Herb

Battelle-Northwest

E. R. Astley

E. O. Ballard

F. E. Bard

A. L. Bement

L. D. Blackburn

R. D. Bourquin

D. C. Bullington

T. D. Chikalla

T. T. Claudson

J. C. Cochran

P. D. Cohn

D. L. Condotta

G. E. Culley

R. E. Dahl, Jr.

J. F. Erben

E. A. Evans

T. W. Evans

R. L. Fish

J. E. Hanson

P. L. Hofmann

J. J. Holmes

J. L. Jackson

R. L. Jackson

R. D. Leggett

F. J. Leitz

H. E. Little

W. W. Little

W. B. McDonald
W. N. McEIroy

J. S. McMahon

K. R. Merckx

M. K. Millhollen

L. A. Pember

R. E. Peterson

W. E. Roake

G. E. Russcher

D. O. Sheppard

R. J . Squires

J. L. Straalsund

J. W. Weber

H. H. Yoshikawa

Legal - 703 Building Legal - ROB, 221-A

Technical Information (5) Technical Publications (3) FFTF File, 703 Bldg. (10) FFTF TPO (List "T") 